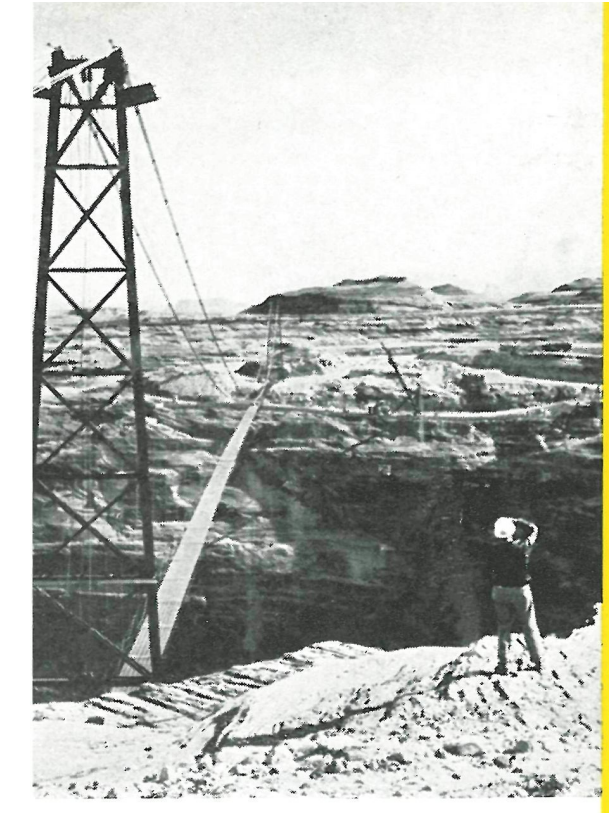

\title{
pasarela Glen Canyon
}

Información amablemente facilitada por la casa Roebling's Sons Corporation de New Jersey, fabricantes de toda clase de cables.

$564 \cdot 12$
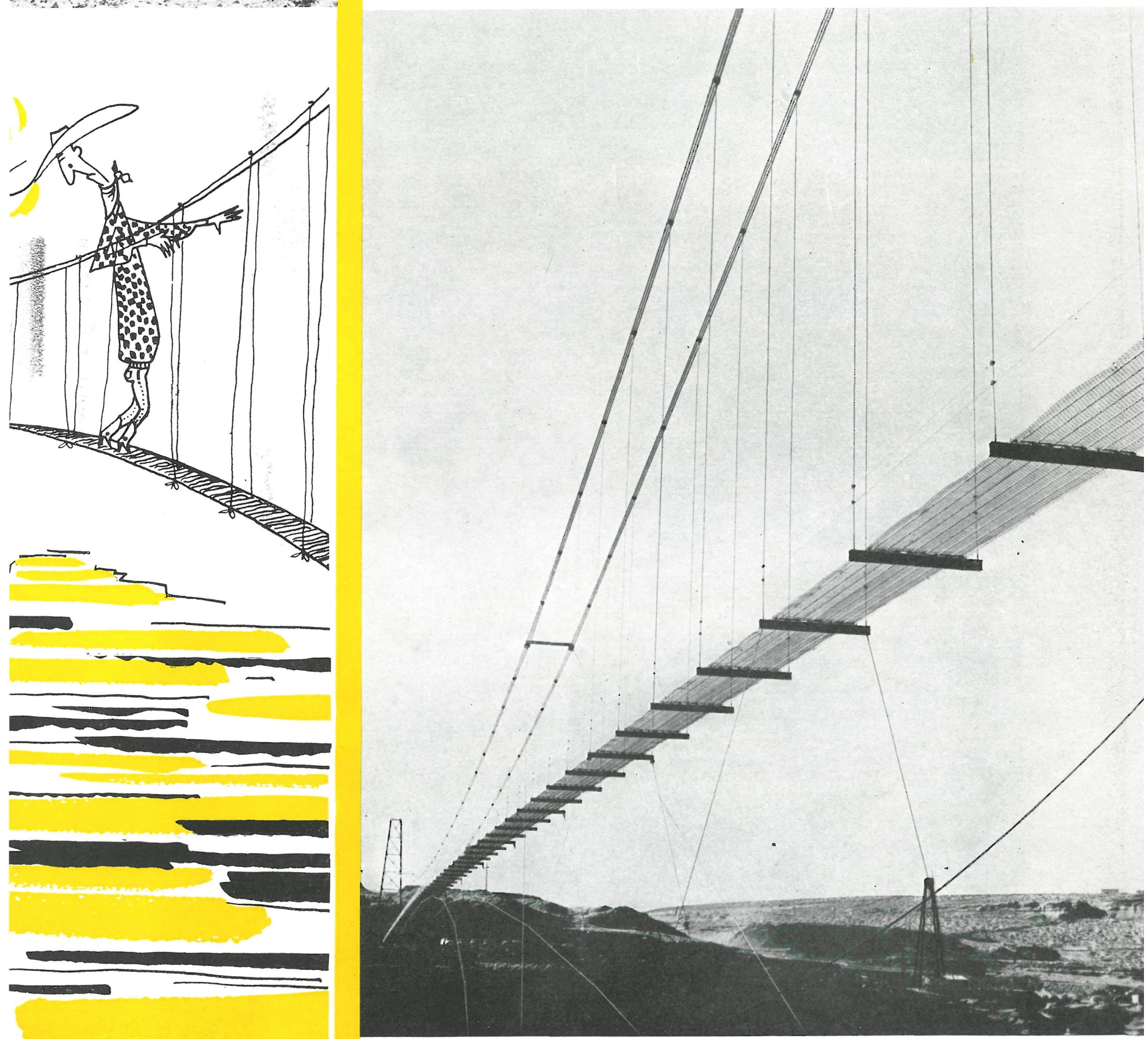

(c) Consejo Superior de Investigaciones Científicas Licencia Creative Commons 3.0 España (CC-by) 


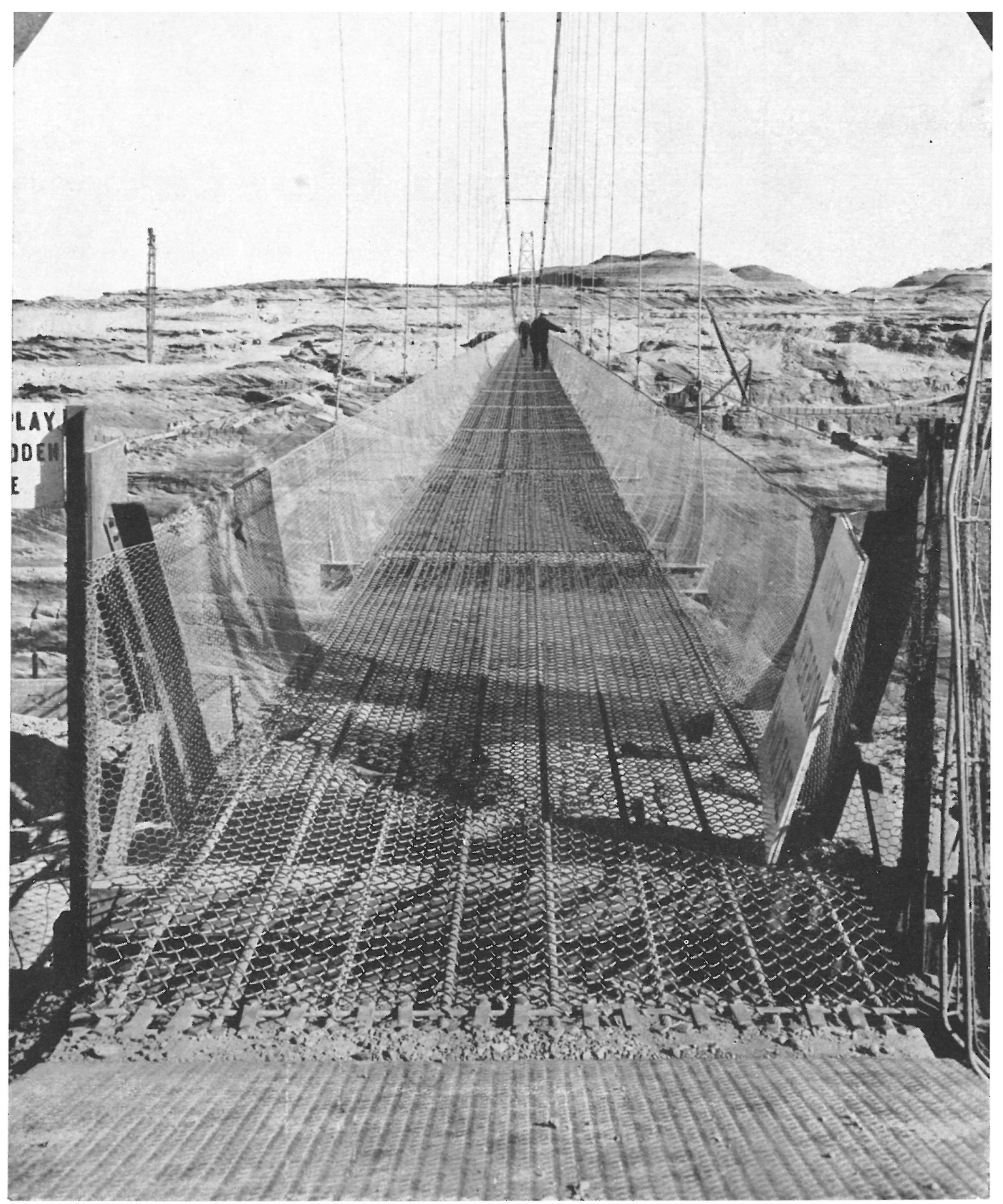

Tablero de tela metálica sobre cables.

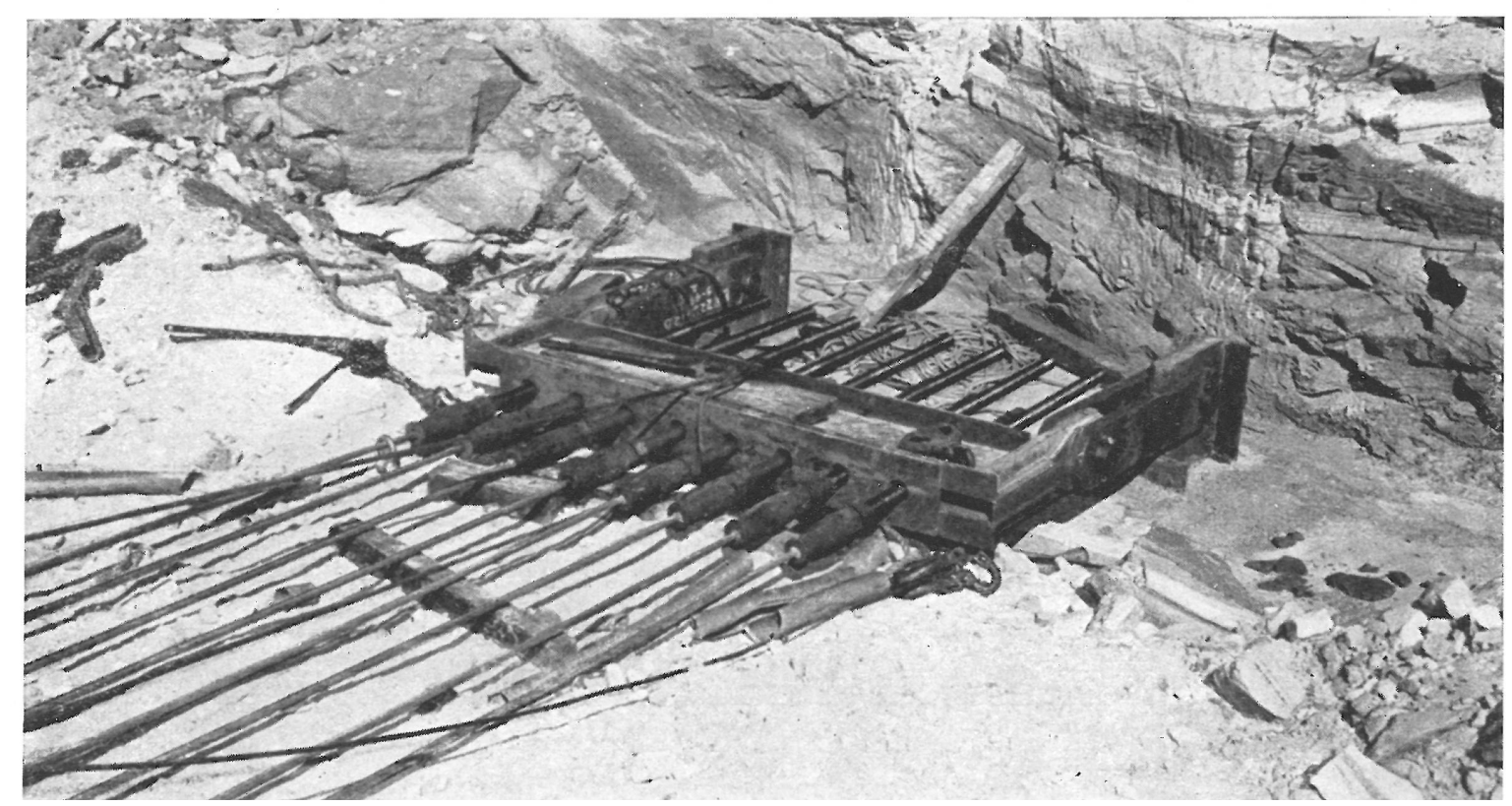

Anclaje de los cables del tablero. 
Para la preparación de los datos complementarios del proyecto de ejecución de la presa del Glen Canyon, se necesitaba una pasarela sobre el río Colorado (Estados Unidos), con objeto de facilitar toda clase de operaciones en el lugar de ubicación de la presa.

En una extensión de unos $320 \mathrm{~km}$, el río no tiene paso superior alguno en esta zona. Estas condiciones particulares de lugar exigieron se construyera una pasarela, de unos $390 \mathrm{~m}$ de longitud, $2,20 \mathrm{~m}$ de tablero, situada a unos $200 \mathrm{~m}$ sobre el río en una acantilada depresión. En.. tre las múltiples soluciones estudiadas se eligió la suspendida, ya que es la más económica y expedita. Este tipo elástico de estructuras suspendidas tiene una gran ventaja sobre los otros tipos rígidos: brevedad y escaso volumen de materiales necesarios. En este caso particular, la construcción de la pasarela sólo duró sesenta días.

La construcción empezó transportando las extremidades de dos cables auxiliares, de $15 \mathrm{~mm}$ de diámetro, utilizando una canoa que los dejó al pie de una de las márgenes del Colorado. De este lugar, y con ayuda de un juego de troclas, se logró llevar las extremidades de estos dos cables a la parte superior de la ladera acantilada. Con estos dos cables auxiliares, se pasaron los seis cables principales sobre los que gravita toda la carga de la pasarela. Estos últimos cables, de $44 \mathrm{~mm}$ de diámetro, galvanizados y estirados, se pasaron sobre las torres levantadas en las extremidades de la pasarela. y se las ancló y tensó hasta lograr la flecha prevista para la catenaria.

De estos cables penden las 64 péndolas que suspenden al tablero de la pasarela por medio de unas viguetas espaciadas a 6 metros. Sobre estas viguetas se han colocado 8 cables de $25 \mathrm{~mm}$ de diámetro, que sirven de apoyo a la tela metálica que forma el tablero. Con objeto de dar la mayor seguridad posible al personal que utilice la pasarela, se ha colocado una tela metálica a cada lado del tablero constituyendo una especie de parapeto.

Para dar mayor estabilidad a la estructura se han colocado debajo del tablero tres cables de $44 \mathrm{~mm}$ de diámetro formando una especie de poligonal invertida con su concavidad hacia abajo. Este arriostramiento da una gran rigidez a la pasarela, incluso durante los momentos de gran viento. Como complemento de rigidez se han puesto cuatro vientos, dos en cada extremidad, que van, del mismo anclaje de los cables inferiores, a los dos paquetes de tres cables cada uno que soportan la pasarela.

Esta obra presenta superficies mínimas opuestas a la acción del viento, ya que hasta la misma base del tablero se ha formado, así como los antepechos, con tela metálica.

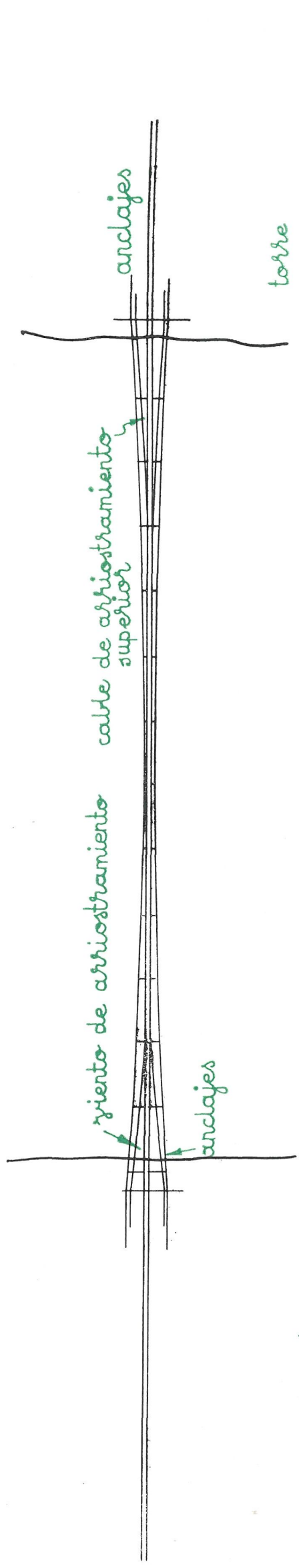




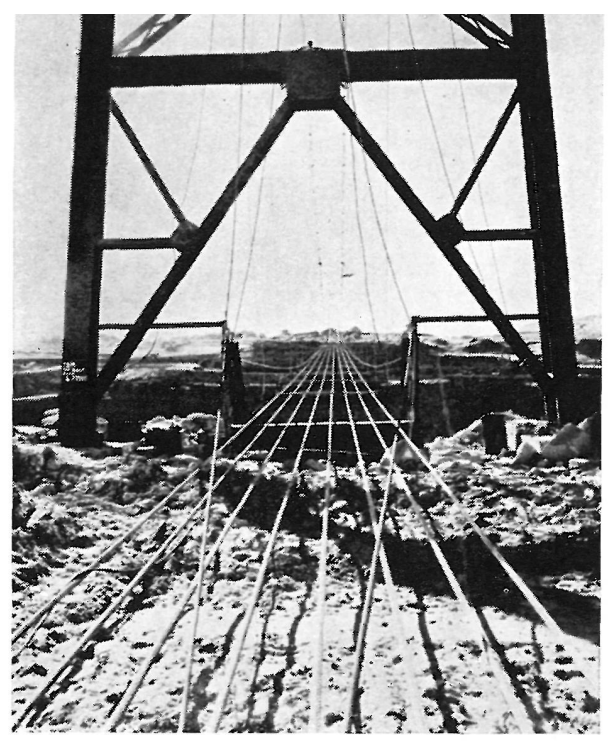

Elementos resistentes del tablero.

Una fase del montaje.

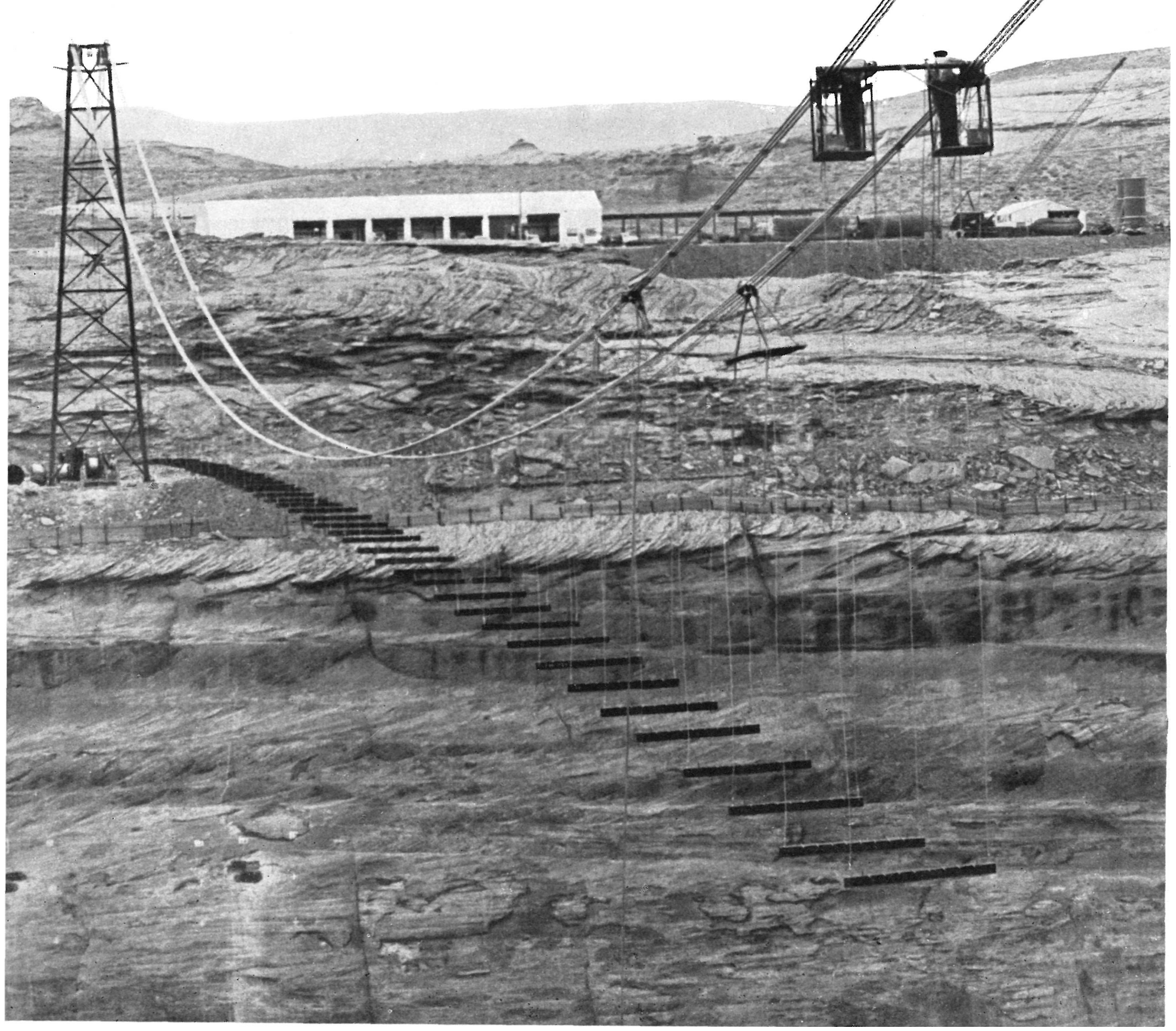




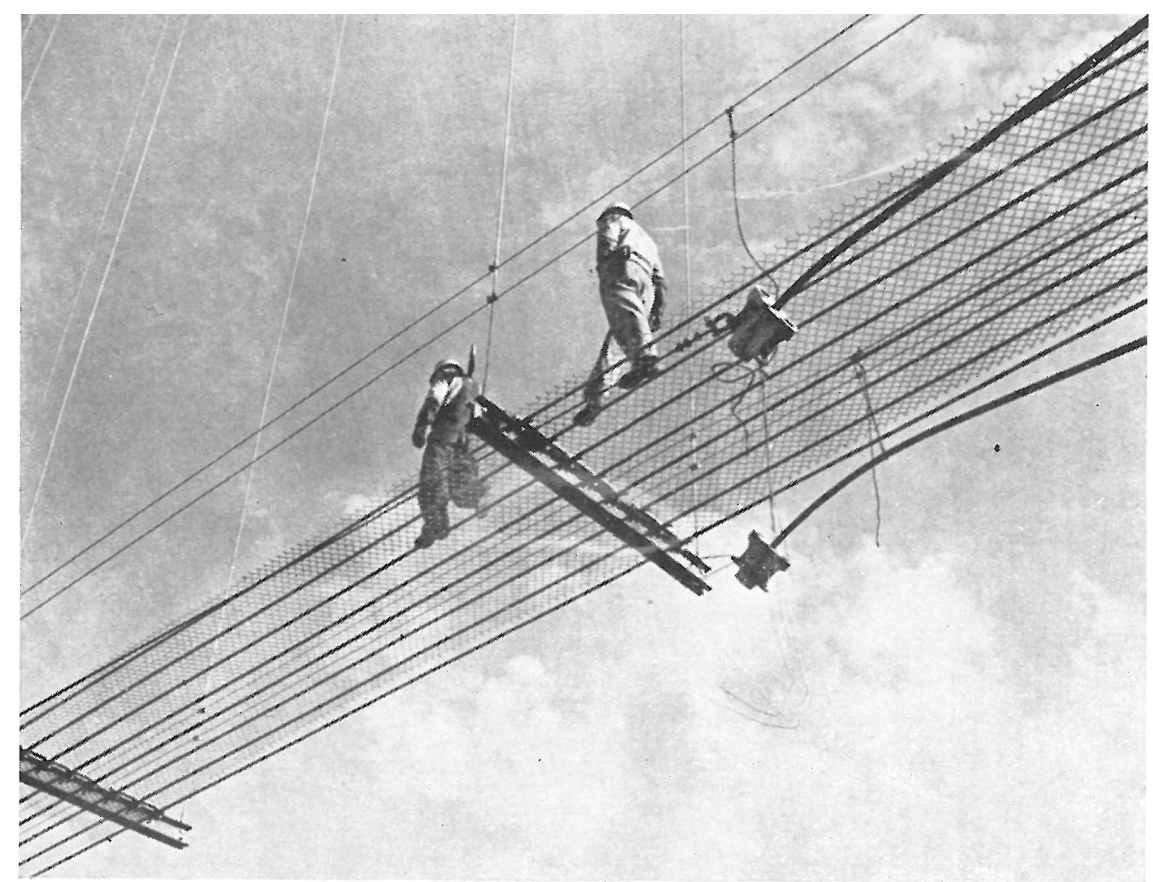

Fotos: A. E. TURNER Y F. S. FINCH
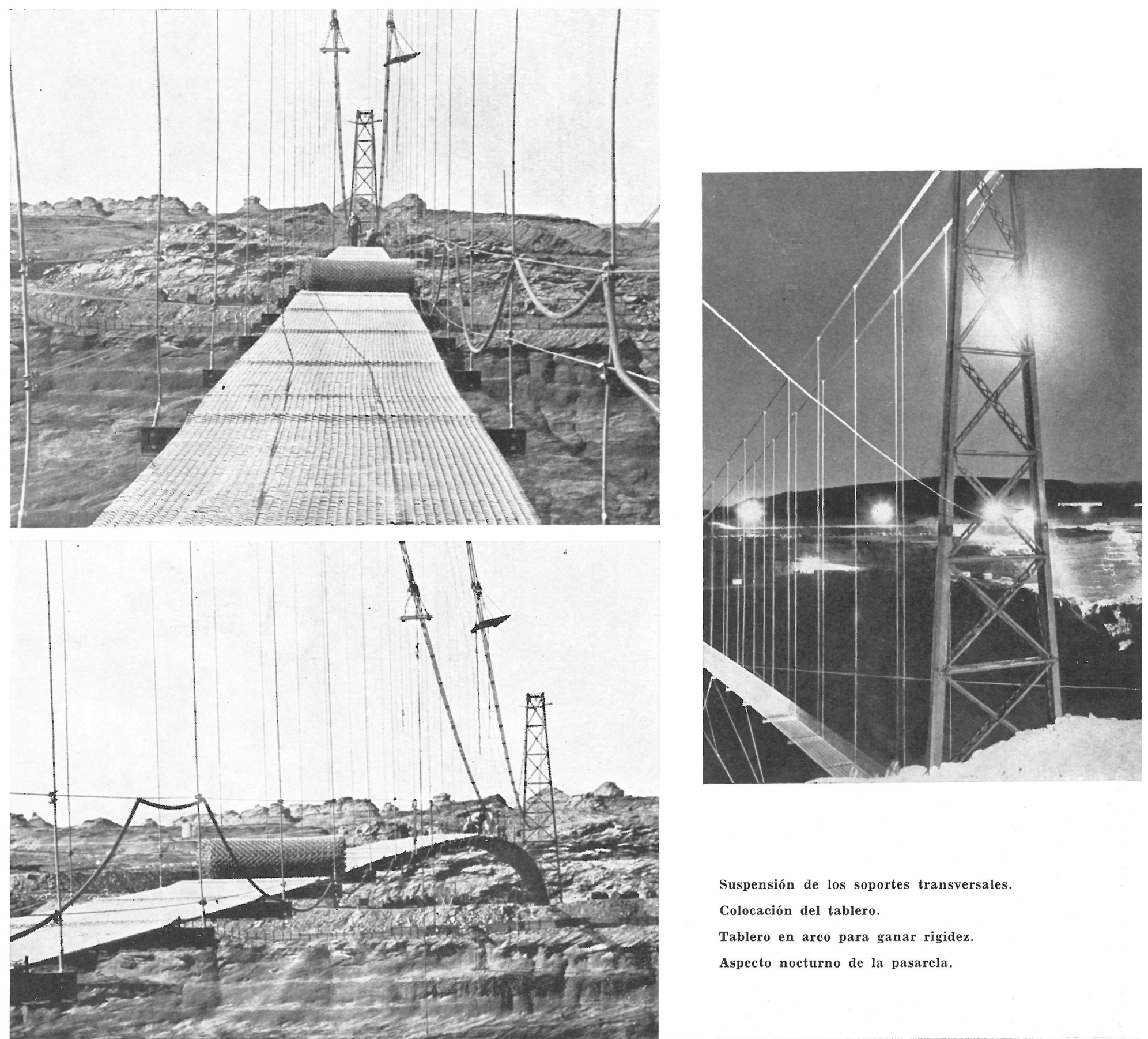

esta obra, la casa Roebling's Sons Corporation ha puesto de manifiesto las grandes posibilidades que se abren al campo de la cablería en la construcción de obras suspendidas, tanto en los puentes de grandes luces como en las más arriesgadas pasarelas, caso particular donde el tiempo permitido para el montaje suele ser muy limitado.

La combinación ordenada de cables, péndolas y tablero permiten sacar un gran partido y belleza en las obras suspendidas, como sucede en la pasarela de Glen Canyon, cuya ilusión es la de una obra maestra y de extrema utilidad y rapidez en su construcción o montaje.

Suspensión de los soportes transversales.

Colocación del tablero.

Tablero en arco para ganar rigidez.

Aspecto nocturno de la pasarela. 